\title{
E-beam Processing of Polymer Matrix Composites for Multifunctional Radiation Shielding
}

\author{
Tan-Hung Hou ${ }^{*}$, J.W.Wilson ${ }^{\dagger}$, B.J.Jensen ${ }^{\ddagger}$, S.A.Thibeault ${ }^{\S}$ \\ NASA Langley Research Center, Hampton, VA 23681 USA \\ C.K. Chang ${ }^{* *}$ \\ Christopher Newport University, Newport News, VA 23606 USA \\ R.L. Kiefer $^{\dagger+}$ \\ College of William and Mary, Williamsburg, VA 23185 USA
}

\begin{abstract}
Aliphatic polymers were identified as optimum radiation shielding polymeric materials for building multifunctional structural elements for in-space habitats. Conceptual damagetolerant configurations of polyolefins have been proposed, but many manufacturing issues relied on methods and materials which have sub-optimal radiation shielding characteristics (for example, epoxy matrix and adhesives). In the present approach, we shall investigate ebeam processing technologies for inclusion of high-strength aliphatic polymer reinforcement structures into a highly cross-linked polyolefin matrix. This paper reports the baseline thermo-mechanical properties of low density polyethylene and highly crystallized polyethylene.
\end{abstract}

\section{Introduction}

$\mathrm{T}$ The development of lightweight multifunctional radiation shielding materials for spacecraft structural applications is critical in future space exploration missions involving humans. Aliphatic polymers such as polyethylene are attractive because the molecular backbones contain high hydrogen content. Hydrogen atoms are effective in breaking up the high energy heavy ion Galactic Cosmic Radiation (GCR) passing through the walls of spacecraft or habitat [1-3]. However, the poor mechanical/thermal performances of aliphatic polymers have limited their application. In the past a sandwich structure using high-density polyethylene fabrics impregnated with epoxy matrix and polyethylene foams was built. However, issues concern the poor bonding of epoxy to the polyethylene fiber and foam interfaces resulted in de-lamination and de-bonding [4,5]. In other cases, the bonding and core strength were enhanced by cross-stitching but required a complicated fabrication process, especially for large irregularly shaped parts.

The present approach is to create a better material match at the aliphatic face sheet/core interface by electron beam irradiation to reduce the de-lamination effect, and thus eliminating the need for the complicated transverse stitching [6]. Electron radiation exposures will create chemically monolithic structure with cross-links. The resulted physical in-homogeneities will provide structural strength and damage tolerance. It is anticipated that this monolithic/in-homogeneous structure will overcome de-bonding, de-lamination, and strength issues while providing efficient radiation shielding.

This paper reports the baseline thermo-mechanical properties of low density polyethylene and highly crystallized polyethylene. Effects of electron dosage on these baseline properties will be investigated in the future. It will be followed by the development of forming highly cross-linked structures within a low-density polyethylene

\footnotetext{
* Senior Research Scientist, Advanced Materials and Processing Branch, MS 226, Member.

${ }^{\dagger}$ Senior Research Scientist, Analytical and Computational Branch, MS 188B, Member.

* Senior Research Scientist, Advanced Materials and Processing Branch, MS 226, Member.

$\S^{\S}$ Senior Research Scientist, Advanced Materials and Processing Branch, MS 226, Member.

*** Professor, Department of Chemistry.

${ }^{\dagger+}$ Professor, Department of Chemistry.
} 
face sheet. A fabrication method for applying such reinforced face sheets to aliphatic polymer closed-cell foams will also be investigated.

\section{Materials ${ }^{1}$}

Three polyethylene (PE) film/sheets and two high density polyethylene (HDPE) Sprectra prepregs are used in this study as tabulated in Table 1 . These materials were all commercially available. The PE films included both amorphous low density (LDPE) and semi-crystalline HDPE materials. Spectra (cyanate ester) prepreg is obtained from Bryte Technologies, Morgan Hill, CA. This prepreg is made of woven 955PT Spectra fabric impregnated with cyanate ester (EX-1515) as matrix resin. Spectra Shield LCR is obtained from Allied Signal, Petersburg, VA. It is made with two cross plies of uni-directional prepreg, sandwiched with protective thermoplastic films.

Table 1. Polyethylene Films and Fabric Prepregs

\begin{tabular}{|l|c|c|c|}
\hline \multicolumn{1}{|c|}{ Material } & $\begin{array}{c}\text { Thickness } \\
\text { (inch) }\end{array}$ & $\begin{array}{c}\text { Fiber Area } \\
\text { Weight }\left(\mathrm{g} / \mathrm{m}^{2}\right)\end{array}$ & Resin content \\
\hline PE film & 0.005 & --- & --- \\
\hline PE sheet & 0.030 & --- & --- \\
\hline HDPE sheet & 0.040 & --- & --- \\
\hline Spectra (Cyanate Ester) & 0.007 & 150 & $50 \%$ \\
\hline Spectra Shield LCR & 0.007 & --- & --- \\
\hline
\end{tabular}

\section{Experimental}

\section{A. Differential Scanning Calorimetry (DSC)}

A Shimadzu DSC-50 calorimeter was used to study the crystallization behavior of the HDPE film and fabric prepregs. A heating rate of $10^{\circ} \mathrm{C} / \mathrm{min}$ was employed in all measurements. In some cases, the specimens were annealed in the DSC at elevated temperatures to study their degradation in the re-crystallization. Both peak melting temperature $\left(\mathrm{T}_{\mathrm{m}}\right)$ and heat of fusion $(\Delta \mathrm{H})$ were taken from the crystalline melt endotherm.

\section{B. Mechanical properties}

A Sintech test frame from MTS Systems was used for the measurements of tensile properties. Load cells from Eaton Corporation with capacities ranging from 50 to 1,000 lbs were used. All measurements were performed at RT. Specimen modulus, ultimate strength and specimen elongation at fracture were recorded for each measurement.

\section{Results and Discussion}

\section{A. Polyethylene film and sheets}

Thermal and re-crystallization behavior of HDPE sheet were investigated by DSC. The specimens were subjected to multiple temperature scans to $180^{\circ} \mathrm{C}$ and the resulting thermograms are compared in Figure 1 . The first scan was from RT to $180^{\circ} \mathrm{C}$ at $10^{\circ} \mathrm{C} / \mathrm{min}$. A clear crystalline melting endothermic peak with a peak melting temperature $\left(\mathrm{T}_{\mathrm{m}}\right)$ at $132^{\circ} \mathrm{C}$ was evident. At the end of the first scan the specimen was left in the DSC cell while cooled down to RT, with no hold at $180^{\circ} \mathrm{C}$. After the specimen reached RT, the second and third scans were carried out in the same fashion. Results are tabulated in Table 2. For the $\mathrm{T}_{\mathrm{f}}=180^{\circ} \mathrm{C}$ case, heat of fusion $(\Delta \mathrm{H})$ in scans 2 and 3 are relatively constant but lower than that measured in the first scan. This could be attributed to superficial crystallinity created by the fabrication process during manufacturing, and is transient in nature. The specimen was not thermally degraded at $180^{\circ} \mathrm{C}$ as evidenced by the constant $\mathrm{T}_{\mathrm{m}}$ and $\Delta \mathrm{H}$, as measured in successive scans.

\footnotetext{
${ }^{1}$ The use of trademarks or names of manufacturers in this paper is for accurate reporting and does not constitute an official endorsement, either expressed or implied, of such products or manufacturer by NASA.
} 

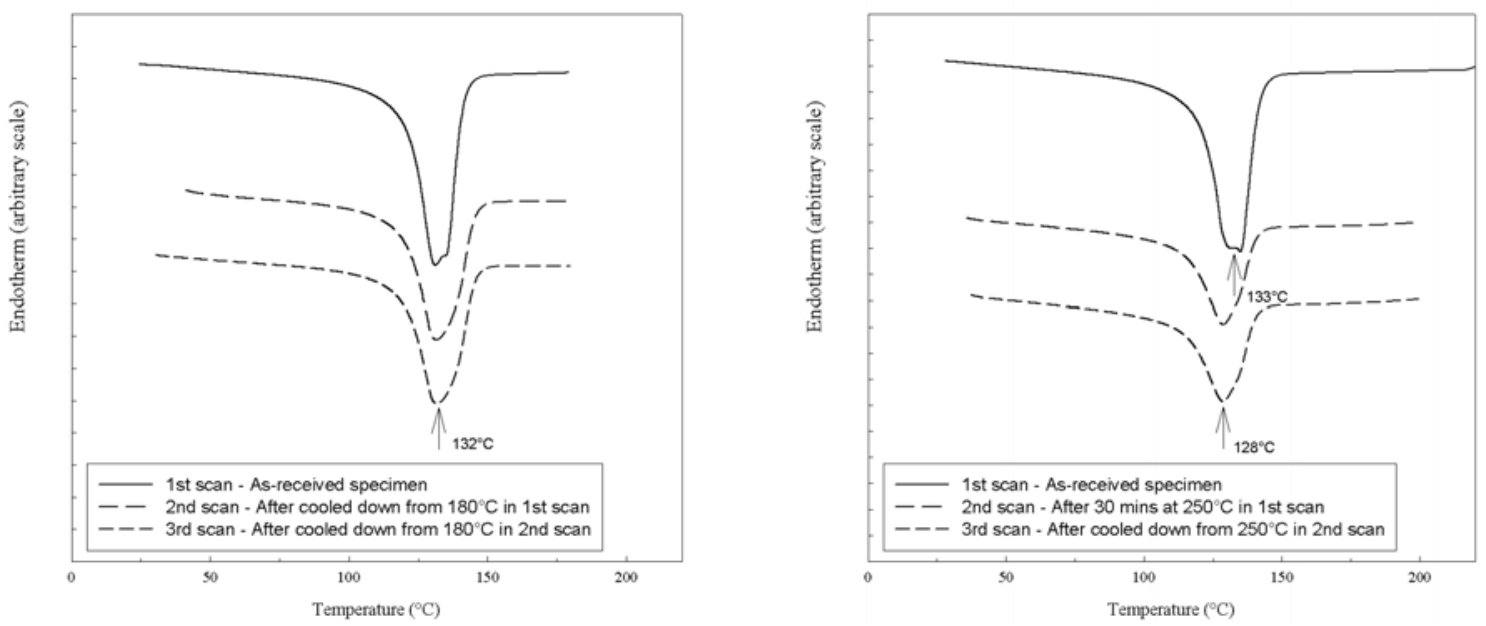

Figure 1. DSC thermograns of HDPE sheet at $180^{\circ} \mathrm{C}$ (left) and $250^{\circ} \mathrm{C}$ (right).

Table 2. Re-crystallization Behavior of HDPE Sheet*

\begin{tabular}{|c|c|c|c|c|}
\hline $\begin{array}{c}\text { Highest scan } \\
\mathrm{T}_{\mathrm{f}}\left({ }^{\circ} \mathrm{C}\right)\end{array}$ & $\begin{array}{c}\text { Scan } \\
\text { sequence }\end{array}$ & $\begin{array}{c}\text { Duration at } \mathrm{T}_{\mathrm{f}} \\
(\mathrm{min})\end{array}$ & $\Delta \mathrm{H}(\mathrm{Joule} / \mathrm{g})$ & Peak $_{\mathrm{m}}\left({ }^{\circ} \mathrm{C}\right)$ \\
\hline \multirow{3}{*}{180} & 1 & 0 & 142.5 & 133 \\
\cline { 2 - 5 } & 2 & 0 & 132.2 & 133 \\
\cline { 2 - 5 } & 3 & 0 & 136.2 & 133 \\
\cline { 2 - 5 } & 1 & 30 & 146.3 & 133 \\
\cline { 2 - 5 } & 2 & 0 & 133.2 & 133 \\
\hline \multirow{3}{*}{200} & 3 & 0 & 135.6 & 133 \\
\cline { 2 - 5 } & 2 & 30 & 144.0 & 128 \\
\cline { 2 - 5 } & 3 & 0 & 94.0 & 128 \\
\hline \multirow{3}{*}{250} & 1 & 30 & 149.4 & 128 \\
\cline { 2 - 5 } & 2 & 0 & 88.1 & 128 \\
\hline
\end{tabular}

*The thickness of HDPE sheet is 0.040"

** DSC scan: from RT to $\mathrm{T}_{\mathrm{f}}$ at $10^{\circ} \mathrm{C} / \mathrm{min}$, followed by the duration time as specified at $\mathrm{T}_{\mathrm{f}}$. Specimen was left in the DSC cell while slowly cooled between the scans.

Figure 1 also depicts the multi-scan thermograms obtained at $\mathrm{T}_{\mathrm{f}}=250^{\circ} \mathrm{C} . \mathrm{T}_{\mathrm{m}}$ and $\Delta \mathrm{H}$ values are included in Table 2. In this case, the specimen was subjected to 30 mins dwell at $250^{\circ} \mathrm{C}$ at the end of first scan before cool down to RT. The specimen was thermally degraded or effected by the creation of oxidation crosslinks during the $250^{\circ} \mathrm{C}$ hold as evidenced by (i) lower $\Delta \mathrm{H}$ (i.e., 88 vs. $135 \mathrm{~J} / \mathrm{g}$ ), (ii) lower $\mathrm{T}_{\mathrm{m}}$ (i.e., $128^{\circ}$ vs. $133^{\circ} \mathrm{C}$ ) as shown in Table 2 , and (iii) broader endothermic peaks when comparing Figures 1 and 2 for the $2^{\text {nd }}$ and $3^{\text {rd }}$ scans.

Although all specimens were cooled down slowly in the DSC from $\mathrm{T}_{\mathrm{f}}$ as reported in Table 2, a similar recrystallization behavior was also observed for the quenched specimens. It is concluded that the HDPE sheet will not be thermally degraded at temperatures below $200^{\circ} \mathrm{C}$ for 30 mins.

Tensile properties of the PE and HDPE materials are tabulated in Table 3. Each specimen was $0.5 \mathrm{~cm}(0.2$ inch) in width and the gauge length was $5.1 \mathrm{~cm}$ (2.0 inch). Test was performed at a head speed of $0.5 \mathrm{~cm} / \mathrm{min}$ using a $22.7 \mathrm{Kg}(50 \mathrm{lb})$ load cell. It is noted that the HDPE exhibited a modulus which was five times as stiff as the amorphous PE (107.1 Ksi vs. $19.9 \mathrm{Ksi}$ ). The HDPE percent elongation at yield was five times less than the amorphous PE counterpart (14.7\% vs. 90.4\%). The HDPE specimens broke at approximately $450 \%$ extension, however, the thermal and re-crystallization behavior were not affected by the stretching. 
Table 3. Baseline Tensile Properties of PE Specimens at RT

\begin{tabular}{|l|c|c|c|}
\hline \multicolumn{1}{|c|}{ Property } & PE film & PE sheet & HDPE sheet \\
\hline Thickness (in) & 0.005 & 0.030 & 0.040 \\
\hline Yield stress (Ksi) & $1.52 \pm 0.05$ & $1.14 \pm 0.02$ & $3.65 \pm 0.72$ \\
\hline Modulus (Ksi) & $19.9 \pm 0.6$ & $18.1 \pm 0.6$ & $107.1 \pm 24.7$ \\
\hline Elongation at yield (\%) & $90.4 \pm 2.8$ & $104.7 \pm 6.2$ & $14.7 \pm 0.1$ \\
\hline
\end{tabular}

\section{B. Spectra (Cyanate Ester) fabric prepreg}

Thermal and re-crystallization behavior of the Spectra (cyanate ester) prepreg were studied by DSC in the same fashion as described above for the HDPE sheet. Results are tabulated in Table 4.

DSC thermograms measured at $170^{\circ} \mathrm{C}$ are shown in Figure 2. Multiple melting peaks at $145^{\circ}$ and $153^{\circ} \mathrm{C}$ were noted in the as-received specimens. The crystalline melting peaks converged to a single peak at a lower $\mathrm{T}_{\mathrm{m}}=$ $135^{\circ} \mathrm{C}$ in the $2^{\text {nd }}$ and $3^{\text {rd }}$ scans, which is very close to the $T_{m}=133^{\circ} \mathrm{C}$ measured for the HDPE sheet specimen in Table 2 above. The initial multi-peak indicates an imperfect crystalline morphology which is attributed to the fabrication process and is again transient in nature. The measured $\Delta \mathrm{H}=56 \mathrm{~J} / \mathrm{g}$ in the $2^{\text {nd }}$ scan is approximately $50 \%$ of the $133 \mathrm{~J} / \mathrm{g}$ for the HDPE sheet specimen (see $180^{\circ} \mathrm{C}$ case in Table 2). This is explained by the fact that the prepreg specimen has $50 \%$ resin content.

Table 4. Re-crystallization Behavior of Spectra (Cyanate Ester) Prepreg*

\begin{tabular}{|c|c|c|c|c|}
\hline $\begin{array}{l}\text { Highest scan } \\
\mathrm{T}_{\mathrm{f}}\left({ }^{\circ} \mathrm{C}\right)\end{array}$ & $\begin{array}{c}\text { Scan } \\
\text { sequence** }^{* *}\end{array}$ & $\begin{array}{l}\text { Duration at } T_{f} \\
\text { (min) }\end{array}$ & $\Delta \mathrm{H}$ (Joule/g) & Peak $\mathrm{T}_{\mathrm{m}}\left({ }^{\circ} \mathrm{C}\right)$ \\
\hline \multirow[t]{3}{*}{170} & 1 & 0 & 111.3 & 144,153 \\
\hline & 2 & 0 & 56.6 & 134 \\
\hline & 3 & 0 & 55.0 & 134 \\
\hline \multirow[t]{3}{*}{200} & 1 & 30 & 118.7 & 144,153 \\
\hline & 2 & 0 & 38.9 & 127 \\
\hline & 3 & 0 & 39.6 & 127 \\
\hline \multirow[t]{3}{*}{225} & 1 & 30 & 115.4 & 145,153 \\
\hline & 2 & 0 & 14.8 & 125 \\
\hline & 3 & 0 & 14.5 & 125 \\
\hline \multirow[t]{3}{*}{250} & 1 & 30 & 115.7 & 145,151 \\
\hline & 2 & 0 & 16.9 & 125 \\
\hline & 3 & 0 & 16.8 & 125 \\
\hline
\end{tabular}

* DSC scan: from RT to $\mathrm{T}_{\mathrm{f}}$ at $10^{\circ} \mathrm{C} / \mathrm{min}$, followed by the duration time as specified at $\mathrm{T}_{\mathrm{f}}$. Specimen was left in the DSC cell while slowly cooled between the scans.

Figure 2 also includes thermograms for the $T_{\mathrm{f}}=250^{\circ} \mathrm{C}$ case. When comparing these two cases, similar characteristics of thermal degradation were observed for the $250^{\circ} \mathrm{C}$ specimen. It is noted from Table 4 that this material degrades at a lower temperature than the HDPE sheet material. At $200^{\circ} \mathrm{C}$, both $\Delta \mathrm{H}$ and $\mathrm{T}_{\mathrm{m}}$ are lower significantly when compared to the $\mathrm{T}_{\mathrm{f}}=170^{\circ} \mathrm{C}$ case. 

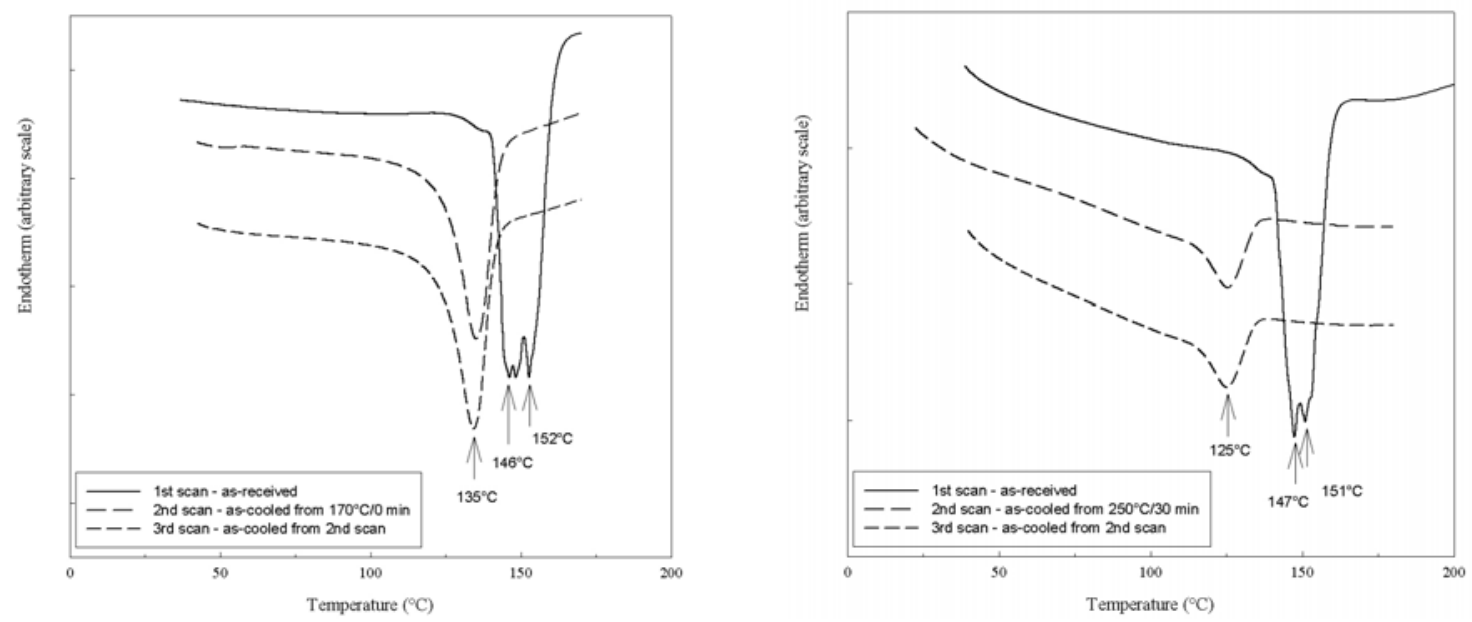

Figure 2 DSC thermograns of Spectra (cyanate ester) prepreg at $170^{\circ} \mathrm{C}$ (left) and $250^{\circ} \mathrm{C}$ (right).

\section{Spectra Shield LCR fabric prepreg}

Thermal and re-crystallization behaviors of the Spectra Shield LCR prepreg were studied by DSC in the same fashion as described above. Results were tabulated in Table 5 and Figure 3. As-received specimen exhibited a heat of fusion of approximately $80 \mathrm{~J} / \mathrm{g}$, which is lower than the $115 \mathrm{~J} / \mathrm{g}$ measured for the Spectra (cyanate ester) prepreg. As pointed out earlier, these values could be superficial and transient in nature. Stable $\Delta \mathrm{H}$ values were obtained for the subsequent $2^{\text {nd }}$, $3^{\text {rd }}$ and $4^{\text {th }}$ scans in Table 5. Measured $\Delta H=56 \mathrm{~J} / \mathrm{g}$ for the Spectra Shield prepreg is close to that measured for the Spectra (cyanate ester) (see Table 4) suggests that both prepregs contain similar resin content.

It was known that the re-crystallization occurred during the slow cooling down period between the scans. It was of interest to see if sample quenching will retard or eliminate the formation of crystalline structures in the HDPE. Sample quenching was achieved by using a dry ice cooled metal block. Results are included in Table 5. It is seen that sample quenching does not affect the re-crystallization kinetics of HDPE.

Table 5. Re-crystallization Behavior of Spectra Shield LCR Fabric*

\begin{tabular}{|c|c|c|c|c|}
\hline $\begin{array}{c}\text { Highest scan } \\
\mathrm{T}_{\mathrm{f}}\left({ }^{\circ} \mathrm{C}\right)\end{array}$ & $\begin{array}{c}\text { Scan } \\
\text { sequence }\end{array}$ & $\begin{array}{c}\text { Duration at } \mathrm{T}_{\mathrm{f}} \\
(\mathrm{min})\end{array}$ & $\Delta \mathrm{H}(\mathrm{Joul} / \mathrm{g})$ & Peak $\mathrm{T}_{\mathrm{m}}\left({ }^{\circ} \mathrm{C}\right)$ \\
\hline \multirow{3}{*}{$\begin{array}{c}170 \\
\text { (slowly cooled) }\end{array}$} & 1 & 0 & 78.4 & 108,150 \\
\cline { 2 - 5 } & 2 & 0 & 55.8 & 113,135 \\
\cline { 2 - 5 } & 3 & 0 & 57.3 & 113,135 \\
\cline { 2 - 5 } & 4 & 0 & 57.6 & 113,135 \\
\hline \multirow{3}{*}{$\begin{array}{c}170 \\
\text { (quenched) }\end{array}$} & 2 & 0 & 82.0 & 108,152 \\
\cline { 2 - 5 } & 3 & 0 & 55.1 & 113,134 \\
\cline { 2 - 5 } & 4 & 0 & 56.1 & 113,134 \\
\hline
\end{tabular}

${ }^{*}$ DSC scan: from RT to $\mathrm{T}_{\mathrm{f}}$ at $10^{\circ} \mathrm{C} / \mathrm{min}$, followed by the duration time as specified at $\mathrm{T}_{\mathrm{f}}$. Specimen was left in the DSC cell while slowly cooled between the scans. 

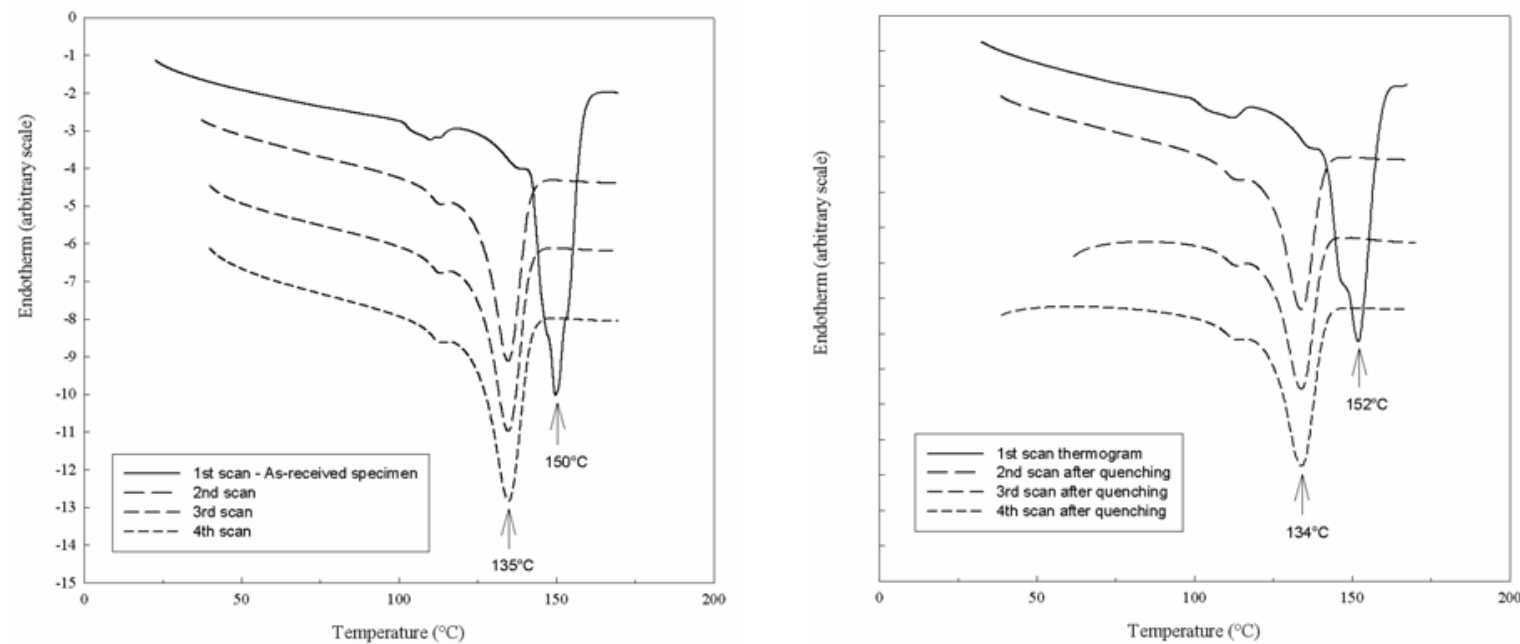

Figure 3. Multi-scan thermograms for Spectra Shield LCR: slow cooling (left) and quenching (right) for specimen between scans.

The interfacial strength between Spectra Shield layers was also investigated by using the peel test [7] in the MTS test frame. Two Spectra Shield layers were bonded by hot press at $240^{\circ} \mathrm{F}$ and 150 Psi for 15 mins. Specimens were then cut into 1 inch in width. Peel test was performed with a $0.025 \mathrm{in} / \mathrm{min}$ head speed and $50 \mathrm{lbs}$ load cell. A typical load vs. position curve is shown in Figure 4. This baseline interfacial strength profile will be compared to those measured for the irradiated specimens in the future.

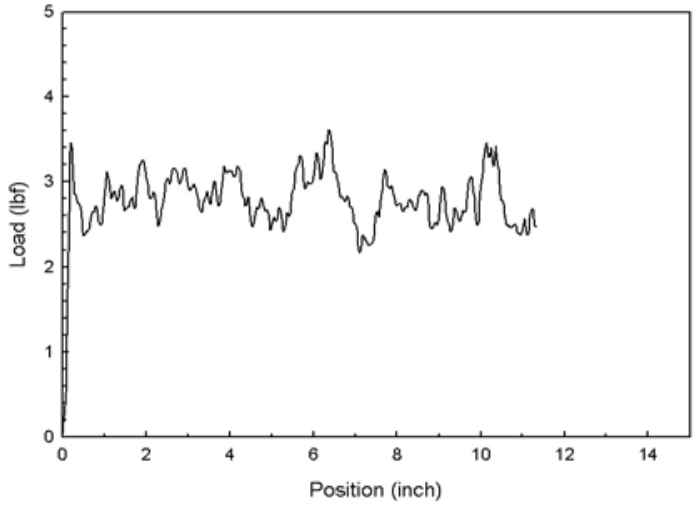

Figure 4. Interfacial strength between Spectra Shield layers bonded by hot press.

\section{Concluding Remarks}

As the first step in the investigation of electron beam processing technologies for inclusion of high-strength aliphatic polymer reinforcement structures into a highly cross-linked polyolefin matrix, the baseline thermal and mechanical properties of both virgin PE and HDPE polymers and fabric prepregs were characterized. Layers of Spectra Shield fabric prepreg were hot press bonded, and the interfacial strength was also measured by the peel test in a MTS test frame. The PE and HDPE films and fabric prepregs can be assembled in a variety of ways and subjected to elecron beam irradiation in the future. Thermal and mechanical properties of these irradiated specimens will be compared to the baseline properties obtained in this report. Properties of the irradiated specimens will serve as building blocks in the fabrication of face sheet/foam core structural subcomponent in this program. 


\section{References}

${ }^{1}$ Wilson, J.W., Miller, J., Konradi, A, and Cucinotta, F.A. (eds.), Shielding Strategies for Human Space Exploration, NASA CP 3360, 1997.

${ }^{2}$ Wilson, J.W., et. Al., “Issues in Deep Space Radiation Protection”, Acta Astronauticsa, Vol. 49, 2001, pp.289312.

${ }^{3}$ Wilson J.W., et. Al., Next Generation Shielding Materials for Earth Neighborhood Infrastructure, AIAA 20036258, Sept. 2003.

${ }^{4}$ E.H. Glaessgen, et al. "Analyses for Debonding of Stitched Composite Sandwich Structures Using Improved Constitutive Models," 42nd AIAA/ASME/ASCE/AHS/ASC Structures, Structural Dynamics, and Materials Conference, AIAA-01-1279-CP, AIAA, Washington, DC, 2001.

${ }^{5}$ L.E. Stanley and D.O. Adams, "Evaluation of Stitched Composite Sandwich Panels Under Interlaminar Loading," Proceedings of the American Society for Composites, Blacksburg, VA, 2001

${ }^{6}$ J.W. Wilson, B.J. Jensen, S.A. Thibeault, Tan-Hung Hou, C.K. Chang, F.F. Badavi, R. Kiefer, E. Saether, E. H. Glaessgen, D.H. Humes and J. Tweed, "E-beam-Cure Fabrication of Polymer Fiber/Matrix Composites for Multifunctional Radiation Shielding”, paper \#2004-6029 presented at AIAA Space 2004 Conference and Exposition, September 28-30, 2004, San Diego, CA.

7,'Standard Test Method for Peel Resistance of Adhesives (T-Peel Test)”, ASTM Standard D1876-01. 